Archived version from NCDOCKS Institutional Repository http://libres.uncg.edu/ir/asu/

\title{
Appalachľan
}

$\bar{B}$ O O N E, N O R T H A R O L N A

\section{The Investment Value Of The Frequency Of Analyst Recommendation Changes For The Ordinary Investor}

\author{
By: Jeffrey Hobbs, Tunde Kovacs, and Vivek Sharma
}

\begin{abstract}
We find that analysts who frequently revise their stock recommendations outperform those who do not. This result holds for portfolios formed on the basis of favorable changes in recommendations as well as unfavorable changes. The frequency of revision captures information incremental to factors known to identify superior recommendations. Although much of the frequently revising analysts' advantage follows events proxied by abnormally high returns or trading volume, it does not appear to derive from more public events such as earnings announcements. Further, these analysts outperform their counterparts even over the short-run, suggesting that this is not simply a "quantity over quality" phenomenon. In summary, our results imply that the superior profitability of frequently revising analysts emanates at least partly from their ability to generate private information using their superior skill. Overall, the ordinary investor is better off following the advice of analysts who revise their recommendations more frequently.
\end{abstract}

Hobbs, J., et al. (2012). "The investment value of the frequency of analyst recommendation changes for the ordinary investor." Journal of Empirical Finance 19(1): 94-108. https://doi.org/10.1016/j.jempfin.2011.09.006. Publisher version of record available at: https://www.sciencedirect.com/science/article/pii/S0927539811000697 


\title{
The investment value of the frequency of analyst recommendation changes for the ordinary investor
}

\author{
Jeffrey Hobbs ${ }^{\mathrm{a}, *}$, Tunde Kovacs ${ }^{c, 1}$, Vivek Sharma ${ }^{\mathrm{b}}$ \\ a Appalachian State University, 416 Howard Street, Rm. 4135 Raley Hall ASU Box 32037, Boone NC, 28607-2037 USA \\ b University of Michigan-Dearborn, 19000 Hubbard Drive, FCS, Dearborn MI, 48126 USA \\ ${ }^{c}$ Northeastern University, CBA-Finance, 360 Huntington Ave., Boston MA, 02115 USA
}

\section{A R T I C L E I N F O}

Keywords:

Analyst recommendation's profitability

Frequency of recommendation changes

Market efficiency

\begin{abstract}
A B S T R A C T
We find that analysts who frequently revise their stock recommendations outperform those who do not. This result holds for portfolios formed on the basis of favorable changes in recommendations as well as unfavorable changes. The frequency of revision captures information incremental to factors known to identify superior recommendations. Although much of the frequently revising analysts' advantage follows events proxied by abnormally high returns or trading volume, it does not appear to derive from more public events such as earnings announcements. Further, these analysts outperform their counterparts even over the short-run, suggesting that this is not simply a "quantity over quality" phenomenon. In summary, our results imply that the superior profitability of frequently revising analysts emanates at least partly from their ability to generate private information using their superior skill. Overall, the ordinary investor is better off following the advice of analysts who revise their recommendations more frequently.
\end{abstract}

\section{Introduction}

One of the oldest questions in finance is whether investment professionals, a.k.a. "experts," can predict or impact the market. Much of the literature suggests that when analysts speak, investors listen. ${ }^{2}$ Dimson and Marsh (1984) find that analysts' predictions of future stock returns are exaggerated, but directionally correct on average. Elton et al. (1986) find that abnormal returns congruent with the nature of the recommendation exist for up to two months after the recommendation is made, while Womack (1996) finds significant excess returns for up to six months after recommendation downgrades. Similarly, Barber et al. (2001, 2003), and Jegadeesh et al. (2004) find that abnormal returns increase with a stock's level or change in average recommendation. These empirical findings are consistent with Grossman and Stiglitz (1980) that information gatherers bring new information to the market to justify their compensation.

Most of the earlier studies have focused on the aggregate performance of recommendations and recommendation revisions. More recently, there is a host of papers providing evidence on cross-sectional differences in recommendations' profitability. One reason for

\footnotetext{
* Corresponding author. Tel.: +1 828262 6241; fax: +1 8282624049.

E-mail addresses: hobbsjc@appstate.edu (J. Hobbs), t.kovacs@neu.edu (T. Kovacs), vatsmala@umich.edu (V. Sharma).

1 Tel.: + 16173733155

2 The empirical research on this topic dates back to Cowles (1933), and was later refined and expanded by Black (1971), Bidwell (1977), and Groth et al. (1979) Logue and Tuttle (1973), among others. These early studies were mixed in their conclusions; some found that recommendations were primarily a reaction to past returns and held little, if any, predictive value, while Black (1971) and Copeland and Mayers (1982) found that highly rated stocks on Value Line experienced positive abnormal returns while low-rated stocks experienced negative abnormal returns. Logue and Tuttle (1973) found predictive value in the sell recommendations, but not in the buy recommendations, made by brokerage houses.
} 
these differences is that some analysts may have better skill or better access to private information. Ertimur et al. (2007) and Loh and Mian (2006) find that analysts who issue more accurate forecasts also make more profitable recommendations. Li (2005), and Mikhail et al. (2004) document that the past performance of an analyst's recommendations tends to persist in the future. Fang and Yasuda (2011) find that top-ranked All-American analysts, who tend to be more experienced than lower-ranked All-American and other analysts, recommend better investments as measured by subsequent risk-adjusted returns. Jegadeesh and Kim (2006) show that analysts who make bolder recommendations than the consensus have a greater price impact. Loh and Stulz (2011) argue that star analysts and more experienced analysts tend to issue more influential stock recommendations than do other analysts. However, Emery and Li (2009) suggest that analyst status can be likened to a "popularity contest" from which subsequent recommendations do not yield positive abnormal profits - and in some cases even yield negative profits.

Another reason for the cross-sectional differences in analysts' recommendations is that some analysts may have distorted incentives. For example, Barber et al. (2007) find that analysts employed by investment banks provide less profitable buy recommendations than analysts employed by independent research firms. Recommendation profitability can also differ based on corporate events. For example, Bradley et al. (2008), and Loh and Stulz (2011) indicate that recommendations issued concurrently with companies' earnings announcements are more influential. Finally, there is evidence that recommendations accompanied by earnings forecasts are more profitable (e.g. Kecskes et al., 2010), and that other items included in analysts' reports, such as price targets and qualitative analysis, also impact the profitability of recommendations (e.g. Asquith et al., 2005).

In this paper we investigate the relative performance of analysts' recommendation changes based on how frequently they revise a typical recommendation. There are at least three reasons to believe that analysts who differ by the frequency of revision may have differential profitability for investors. Analysts compare their own assessment of a firm's fundamental value with the market price and revise their recommendation when they see a substantial change relative to their outstanding recommendation. It is possible that some analysts have better knowledge of the industry, more timely access to management, suppliers, and customers, or alternatively are able to process publicly available information more efficiently than others. We expect that analysts with an advantage in information or skill are able to identify mis-valuation in stock prices more often, and thus revise their recommendations more frequently. Therefore, trading on their recommendations will be more profitable to investors in terms of exploiting short-term mispricing. Frequent recommendations can also reflect more timely communication with investors, an aspect of analyst performance deemed important by Institutional Investor survey participants (Leone and Wu, 2007).

Alternatively, one could argue that analysts who revise their recommendations more often are acting on noise, perhaps owing to overconfidence (Barber and Odean, 2000; Odean, 1998). Accordingly the analysts who revise recommendations less frequently are the ones who actually uncover new information. Furthermore these analysts may be more cautious and perhaps use multiple valuation screens before making their recommendation revisions. By this reasoning, investors may be better off following the recommendations of analysts with less frequent revisions.

Additionally, it is possible that the type of information the analyst has determines how frequently he or she changes recommendations. If this is the case, analysts with short-term information will more frequently change recommendations while analysts with long-term information will not change recommendations as frequently. Therefore investors will be better off in the short-run following the recommendations of analysts with more frequent revisions. However, the analysts with less frequent revisions may provide more value to investors in the long-run.

Our study examines whether the frequency of recommendation revisions relates to their profitability. We attempt to generate a profitable trading strategy for investors by focusing on performance differences at the analyst level, similar in spirit to Li (2005), Barber et al. (2007), and Fang and Yasuda (2011). The findings herein could potentially help the ordinary investor, who has limited time and resources and is likely to follow just one or a few analysts, identify superior performers from the universe of all sellside analysts based on a simple measurable yardstick of frequency of recommendation changes in the recent past. Our study also contributes to the academic literature by providing information about the sources of competitive advantage in sell-side equity research. Finally, our work complements some of the findings in the buy-side literature. Yan and Zhang (2009) find that the positive alphas associated with institutional investors are concentrated in those institutions whose focus is on short-term, rather than long-term, profits. Although the work environment of sell-side analysts substantially differs from that of buy-side managers in terms of regulations, bases for evaluation and compensation, employers, and responsibilities (Schipper, 1991), to the ordinary investor the primary question remains unchanged: which type of analyst yields more profitable recommendations?

We then explore some of the potential reasons for why frequently revising analysts yield greater returns. The source of this higher profitability could, for example, be an enhanced ability to interpret publicly available information. However, we find no statistical difference between frequently and infrequently revising analysts in the percentage of recommendation changes that occur around earnings announcements, and the difference in profitability between the two groups is not concentrated in those revisions that are made during earnings announcement periods. Additionally, it is possible that frequently revising analysts respond more quickly to other information events proxied by abnormally large stock returns or trading volume (in the spirit of Leone and Wu, 2007). Indeed, we find that frequently revising analysts respond more quickly both to large stock price changes and above-average turnover than do infrequently revising analysts, and those responses yield much higher profits. Finally, we examine whether the underperformance of infrequently revising analysts is driven simply by their relative lack of revisions. We compare the short-run profitability of the two analyst groups by excluding from our portfolios all outstanding recommendations older than two months, and find very similar results to our "long-run" analysis. Thus it appears that those analysts who most frequently revise their recommendations do better even in the short-run; they do not outperform their counterparts simply on the basis of quantity. Overall, our results suggest that at least part of the superior profitability of frequently revising analysts' recommendations derives from a better knowledge of the industry or companies they cover or from more timely access to management, suppliers, and customers. 
The remainder of the paper is organized as follows. Section 2 describes the data and methods used. Section 3 documents the main results, followed by robustness checks in Section 4 . Section 5 investigates the source of the profitability of recommendations made by analysts with more frequent revisions. Section 6 concludes the paper.

\section{Material and methods}

The analysts' recommendations data are extracted from the Institutional Brokers' Estimate System (IBES, hereafter) detail recommendation files for all U.S. firms with a Center for Research in Security Prices (CRSP, hereafter) share code of 10 or 11 . Our sample period begins in November, 1993, when the IBES recommendation data file coverage commences, and ends in 2006. We match the Committee on Uniform Securities Identification Procedures (CUSIP, hereafter) code from the IBES files with the CRSP historical CUSIP. To maximize the sample size we first match using 8 character length CUSIPs, followed by 6 character length CUSIPs. Ljungquist et al. (2009) document problems related to recommendations issued by analysts who are anonymous (without any analyst code in the IBES files). Therefore, we include only those recommendations that have a non-missing analyst code. Since the reiteration of a recommendation is of little investment consequence to investors, we delete all reiterations. Thus, our sample is restricted to those stocks whose current recommendations are different from their previous recommendations. A recommendation is assumed to be valid until the IBES files record a stop on the stock by the analyst or until that recommendation has remained outstanding for more than a year. In order to relate the frequency of recommendation changes to their profitability, we concentrate on analysts with at least 3 years of history in the IBES files. ${ }^{3}$ To measure how frequently an analyst revises recommendations, we compute the average length of time of his or her outstanding recommendations across all the covered stocks in the previous 12 months. This calculation is updated on a monthly basis. The shorter (longer) the length of the average recommendation, the more (less) frequently the analyst revises his or her recommendations.

Starting with IBES analyst recommendation data from January $1997,{ }^{4}$ we create one long portfolio, consisting of recommendation upgrades, and one short portfolio, consisting of recommendation downgrades, for each analyst in our sample. ${ }^{5}$ We form these portfolios based solely on upgrades and downgrades because changes in recommendations have been found to be more informative than the actual level of the recommendations (Jegadeesh et al., 2004). We define upgrades and downgrades with the help of the following scale:

\begin{tabular}{lllll}
\hline Strong buy & Buy & Hold & Underperform
\end{tabular}

Within the context of the foregoing table, any recommendation that represents a move to the left, relative to the recommendation that most recently preceded it, is counted as an upgrade and any move to the right is counted as a downgrade.

In addition to recommendation changes we also include initiations - that is, first-time recommendations of stocks by analysts. There is obviously no previous recommendation against which to benchmark initiations, so we classify a first-time recommendation of "strong buy" or "buy" as an upgrade and a first-time recommendation of "underperform" or "sell" as a downgrade.

A stock is added to the long (short) portfolio at the end of the day it is upgraded (downgraded). This ensures that announcement day effects are ignored as most retail investors are unable to act on the recommendation until the end of the day of the upgrade/ downgrade, and is consistent with previous research (e.g. Barber et al., 2001, 2003, 2007). For robustness we alternatively included the announcement day effect, and our results remain qualitatively the same as those shown in Section 3 of this paper. Each stock remains in its long or short portfolio until a subsequent reversal (from upgrade to downgrade or vice-versa) shifts it into the other. The stock leaves the portfolio the day the analyst ceases to cover it or when the most recent recommendation has remained unchanged for more than a year.

Each stock added to a long or short portfolio gets an equal $\$ 1$ of investment. This ensures that all recommendations are treated equally, without any need for daily rebalancing (such rebalancing would be necessary and costly to implement in a strategy of equal-weighting). It could also be argued that value-weighting may not be suitable for this study, since analyst recommendations have been shown to be more valuable for smaller stocks (Barber et al., 2001). Barber et al. (2007) also follow the same portfolio weighting scheme. Assuming an equal dollar investment in each recommendation, the return to the long portfolio on date $\tau$ is given by:

$$
R_{p \tau}=\frac{\sum_{i=1}^{n_{\tau}} x_{i \tau} R_{i \tau}}{\sum_{i=1}^{n_{\tau}} x_{i \tau}},
$$

where $R_{i \tau}$ is the gross date $\tau$ return on stock $i, n_{\tau}$ is the number of stocks in the portfolio, and $x_{i \tau}$ is the compounded daily return of stock $i$ from the close of trading on the day of the recommendation through day $\tau-1$ (the variable $x_{i \tau}$ equals 1 for a stock

\footnotetext{
${ }^{3}$ For robustness we also used analysts with 1 and 2 years of history on IBES files and found qualitatively similar results.

${ }^{4}$ Our statistical tests commence starting 1997 since we require at least 3 years of analysts' recommendation history and the IBES files begin near the end of 1993.

${ }^{5}$ We also investigate how our results are affected if we adopt a firm-analyst approach instead of using analyst level portfolios. In unreported analysis we find qualitatively similar results to the ones reported in the paper.
} 
recommended on day $\tau-1$ ). This calculation yields a time-series of daily returns for the long portfolio. The time-series for the short portfolio is determined analogously. Daily portfolio returns are compounded to compute monthly returns as follows:

$$
R_{p t}=\left[\prod_{\tau=1}^{n}\left(1+R_{p \tau}\right)\right]-1
$$

where $n_{t}$ is the number of trading days in the month $t$ and $R_{p t}$ is the raw monthly return for the portfolio.

We group analysts by their frequency of recommendation changes and then compute each group's overall abnormal return as a time-series average of cross-sectional means of abnormal return (in the spirit of the Fama and MacBeth (1973) regression framework) of long and short portfolios over the 1997-2006 period. We compute abnormal returns using the CAPM, the Fama and French (1993) three factor model, and the Carhart model (1997) that supplements the Fama and French three factor model with a momentum factor. Although recent studies focus primarily on the three- and four-factor models, we also include the CAPM for completeness. In order to compute the abnormal return of the analyst portfolios using the Carhart model, we regress the portfolio's monthly excess returns on the market's excess returns, firm size, book-to-market ratio, and momentum, all downloaded from Kenneth French's website, as follows:

$$
r_{p, t}-r_{f, t}=\alpha_{p}+\beta_{p}\left(r_{m, t}-r_{f, t}\right)+\gamma_{p}\left(s m b_{t}\right)+\delta_{p}\left(h m l_{t}\right)+\omega_{p}\left(m o m_{t}\right)+\varepsilon_{p, t},
$$

where the dependent variable is the return on portfolio $p$ in month $t$ net of the risk-free rate, and the factor portfolios include the returns of four zero-investment strategies. In particular, the first factor, $r_{m, t}-r_{f, t}$ denotes the excess return on the market portfolio over the risk-free rate, the second factor, smb, is the return difference between small and large capitalization stocks, the third factor, $\mathrm{hml}$, is the return difference between high and low book-to-market stocks, and the fourth factor, mom, is the return difference between stocks with high and low past returns. The asset pricing model assumes that $\alpha_{i}=0$ and $\varepsilon_{i, t}$ are orthogonal to the information known at time $t-1$ so the risk-adjusted return (abnormal return) for portfolio $\mathrm{p}$ at time $\mathrm{t}$ is

$$
A R_{p 4, t}=r_{p, t}-r_{f, t}-\hat{\beta}_{p}\left(r_{m, t}-r_{f, t}\right)+\hat{\gamma}_{p}\left(s m b_{t}\right)+\hat{\delta}_{p}\left(h m l_{t}\right)+\hat{\omega}_{p}\left(m o m_{t}\right)=\hat{\alpha}_{p}+\hat{\varepsilon}_{p, t}
$$

In other words, the abnormal return for each portfolio in each month is the sum of the monthly residual and the intercept from the regression. Following a similar procedure we compute the abnormal return under the Fama and French (1993) three factor model as follows:

$$
A R_{p 3, t} \equiv r_{p, t}-r_{f, t}-\hat{\beta}_{p}\left(r_{m, t}-r_{f, t}\right)+\hat{\gamma}_{p}\left(s m b_{t}\right)+\hat{\delta}_{p}\left(h m l_{t}\right)=\hat{\alpha}_{p}+\hat{\varepsilon}_{p, t}
$$

Last, the abnormal return under the CAPM is computed as follows:

$$
A R_{p \beta, t} \equiv r_{p, t}-r_{f, t}-\hat{\beta}_{p}\left(r_{m, t}-r_{f, t}\right)=\hat{\alpha}_{p}+\hat{\varepsilon}_{p, t},
$$

We use the approach outlined earlier instead of an event-time approach because we are primarily interested in the analyst level rather than the recommendation level analysis. To the ordinary investor, who is likely to follow a very small number of stock analysts, the question of whom to follow is central, and thus it is our main research question. Additionally, an event study introduces the thorny issue of what types of information different analysts use; for example, it could be the case that infrequently revising analysts tend to use long-term information while short-term analysts use short-term information. By employing a maximum one year holding period for each recommendation and an aggregate portfolio strategy we are able to determine, over the long-run, which analysts are more profitable. We also examine whether the differences we find are explained by factors already noted in the sell-side analyst literature.

\section{Results}

\subsection{Main results}

\subsubsection{Descriptive statistics}

In panel A of Table 1 , we sort all analysts in our sample into quintiles by their frequency of recommendation changes. If an analyst stops covering a stock or has not revised its recommendation in at least one year then we drop the initial recommendation before sorting. The first quintile represents the analysts who most frequently change recommendations for those stocks that they cover. The mean, median, and standard deviation are given for the overall sample as well as for each quintile. At an average point in time the average analyst's recommendations are outstanding for around 5 months. ${ }^{6}$ However, there is substantial variation

\footnotetext{
${ }^{6}$ Our average length of a recommendation is somewhat longer that the one reported in Barber et al. (2001) who find the mean time between a recommendation and its revision to a new rating is in the low 100-day range in the 1985-1996 period based on recommendations in the Zacks Investment Research database (page 538 ). On the other hand, our figure is lower than the average length of historical recommendations reported in Loh and Stulz (2011) and Malmendier and Shanthikumar (2007) possibly since we restrict the validity of a recommendation to no more than one year.
} 
Table 1

Descriptive statistics. Panel A of this table reports the number of days an average analyst's recommendations have been outstanding. We extract analyst recommendations data from IBES detail recommendations files. We require at least three years of historical information for each analyst to be included in the sample. The recommendation ceases to be valid if the analyst stops coverage for the stock or if the recommendation has remained outstanding for more than a year. Analysts are sorted into quintiles at the end of each month on the basis of average length of recommendations outstanding computed across all stocks in the analysts' portfolio. We report below the time-series statistics of the monthly cross-sectional averages computed from 1997 to 2006 . In panel B, we report year-byyear descriptive statistics of analyst-portfolio-months included in our sample. The first three columns show the total number of analyst-months classified as long and short portfolios each year. For each analyst we form one long and one short portfolio. A stock gets included in the long (short) portfolio when an analyst issues an upgrade (downgrade) on the stock. A subsequent downgrade (upgrade) may shift the stock to short (long) portfolio. The stock is dropped from the portfolio if the analyst stops providing coverage or if the recommendation has remained in the portfolio for a year since the last upgrade (downgrade). The fourth column shows the number of unique analysts in the sample. The fifth column reports the mean (median) of stocks' market capitalization in the analysts' portfolios. The sixth column reports the mean (median) number of analysts following each stock in the analyst portfolios. The last column shows the mean (median) number of stocks in analysts' portfolios.

\begin{tabular}{|c|c|c|c|c|c|c|c|}
\hline \multicolumn{8}{|c|}{ Panel A: Days recommendation is outstanding } \\
\hline \multicolumn{3}{|c|}{ Portfolios } & \multicolumn{2}{|c|}{ Mean } & \multicolumn{2}{|l|}{ Median } & Std. dev \\
\hline \multicolumn{3}{|c|}{ F1 (most frequent) } & \multicolumn{2}{|c|}{79.19} & \multicolumn{2}{|l|}{80.86} & 8.77 \\
\hline \multicolumn{3}{|c|}{$\mathrm{F} 2$} & \multicolumn{2}{|c|}{128.82} & \multicolumn{2}{|l|}{130.58} & 8.68 \\
\hline \multicolumn{3}{|l|}{ F3 } & \multicolumn{2}{|c|}{157.61} & \multicolumn{2}{|l|}{158.50} & 7.84 \\
\hline \multicolumn{3}{|l|}{ F4 } & \multicolumn{2}{|c|}{187.74} & \multicolumn{2}{|l|}{187.78} & 7.85 \\
\hline \multicolumn{3}{|c|}{ F5 (least frequent) } & \multicolumn{2}{|c|}{246.49} & \multicolumn{2}{|l|}{245.27} & 8.20 \\
\hline \multicolumn{3}{|c|}{ Overall } & \multicolumn{2}{|c|}{159.94} & \multicolumn{2}{|l|}{157.62} & 60.62 \\
\hline \multicolumn{8}{|c|}{ Panel B: Descriptive statistics of analyst-portfolios-months included in our sample } \\
\hline \multirow[t]{2}{*}{ Year } & \multicolumn{3}{|c|}{ Analyst-months } & \# of & \multirow[t]{2}{*}{ Size (\$ millions) } & \multirow{2}{*}{$\begin{array}{l}\# \text { of } \\
\text { analysts/stock }\end{array}$} & \multirow{2}{*}{$\begin{array}{l}\text { \# of stocks } \\
\text { in analyst } \\
\text { portfolios }\end{array}$} \\
\hline & Long & Short & Total & analysts & & & \\
\hline 1997 & 9382 & 11,045 & 20,427 & 1171 & $6232.99(1846.90)$ & $5.80(5.17)$ & $7.64(7.00)$ \\
\hline 1998 & 10,563 & 13,187 & 23,750 & 1409 & 7375.43 (1930.93) & $6.18(5.67)$ & $7.47(7.00)$ \\
\hline 1999 & 11,905 & 14,673 & 26,578 & 1557 & $10,720.22(2,345.54)$ & $7.41(6.80)$ & $7.15(6.00)$ \\
\hline 2000 & 11,762 & 15,776 & 27,538 & 1718 & $13,092.40(2,791.56)$ & $7.24(6.60)$ & $6.67(6.00)$ \\
\hline 2001 & 13,051 & 15,875 & 28,926 & 1813 & $11,062.62(2791.85)$ & $7.31(6.67)$ & $6.05(5.00)$ \\
\hline 2002 & 13,815 & 15,696 & 29,511 & 1809 & $10,106.07$ (2867.35) & $8.30(7.63)$ & $6.72(6.00)$ \\
\hline 2003 & 14,210 & 14,659 & 28,869 & 1701 & $10,529.80(3249.31)$ & $8.73(8.00)$ & $7.36(7.00)$ \\
\hline 2004 & 13,639 & 15,699 & 29,338 & 1647 & $10,783.28(3486.14)$ & $7.82(7.10)$ & $6.58(6.00)$ \\
\hline 2005 & 14,410 & 16,317 & 30,727 & 1748 & $10,314.64(3226.31)$ & $6.98(6.45)$ & $5.93(5.00)$ \\
\hline \multirow[t]{2}{*}{2006} & 14,531 & 16,883 & 31,414 & 1841 & $10,044.61(3100.42)$ & $6.60(6.00)$ & $5.89(5.00)$ \\
\hline & 127,268 & 149,810 & 277,078 & 3923 & & & \\
\hline
\end{tabular}

across analysts since this figure amounts to less than three months for analysts in the first quintile, while it is close to eight months for analysts in the fifth quintile.

In panel B, we provide descriptive statistics of the long and short portfolios that we construct in response to analysts' revisions. There are 3923 unique analysts with a total of 277,078 long and short portfolio-months over the 120 months in our sample period. The number of long and short portfolio-months is approximately equally divided. The slight difference occurs because some analysts may have only long or short portfolios in a particular month due to their most recent upgrades or downgrades. The mean (median) size of a stock in our analysts' portfolio is around \$10 billion (\$3 billion) during the sample period. A typical analyst holds an average of 7 stocks with active recommendations in his or her portfolios. The typical stock is covered by around 7 analysts.

Table 2 provides descriptive statistics of stocks in each quintile in both the long and short analyst portfolios. For each variable, we use monthly data extracted from CRSP or COMPUSTAT, and we detail each variable's construction in the text portion of Table 2. Within the subset of long portfolios (panel A), the analysts who change their recommendations least frequently tend to cover larger stocks with lower price-to-earnings ratios, higher one-year sales growth, and lower buy-and-hold returns over the previous six months. Analysts in the first quintile a.k.a. those who most frequently change their recommendations tend to cover stocks with relatively high $\mathrm{P} / \mathrm{E}$ ratios, lower sales growth, and relatively high past returns. Note, however, that these differences are not staggering; the stock characteristics remain roughly similar across different analyst quintiles. Within the subset of short portfolios (panel B), the frequency of recommendation changes has the same relationship with firm size and P/E ratio as it did in panel A. However, there are two notable differences; the analysts who least frequently revise tend to have stocks with relatively low recent sales growth and relatively high returns. There is no difference in the number of analysts covering the average stock in either the long or short portfolios. In addition, within both portfolios there is a negative relationship between the frequency of revisions and the number of analysts employed per brokerage firm. This means that analysts who work for smaller brokerage firms tend to change their stock recommendations more frequently than those who work for larger firms.

Finally, the last four columns of both panels display average factor loadings from regressing excess returns of analysts' long and short portfolios on factors from Carhart's (1997) four-factor model. Within long and short portfolios, there is no relationship in our measure of recommendation revision frequency and average excess return, $s m b$, and mom factor loadings. However, the 
Table 2

Characteristics of long and short portfolios formed on the basis of the average length of recommendations outstanding in analyst portfolios. For each analystmonth, we sort analysts into quintiles on the basis of average length of recommendations outstanding computed across all stocks in the analysts' portfolio. Each column reports the mean of various characteristics of stocks and analysts computed across all analyst-month-portfolios in each quintile. Size is the average market capitalization of stocks in the analyst portfolios. Each stock's market capitalization is computed by multiplying its shares outstanding by the price extracted from the monthly CRSP files. $\mathrm{P} / \mathrm{E}$ is the average price-earnings ratio of stocks in the analyst portfolio. To compute $\mathrm{P} / \mathrm{E}$ ratio, price is taken at the end of month price extracted from CRSP files and earnings is extracted from annual COMPUSTAT files (data item \#233). We use the most recent earnings if the firm's fiscal year is within 90 days of the current month - otherwise we use the prior year's earnings and end-of fiscal year price per share. Sales growth is the average sales growth of the firms in the analyst portfolios. To compute sales growth, we divide the current fiscal year's sales with the previous fiscal year's sales. Sales are extracted from the COMPUSTAT annual files (data item \#12). Similar to the P/E ratio, we use the most current sales growth if the firm's financial year ends within 90 days of the current month; otherwise we use the prior year's sales growth. Past return is the average buy-and-hold return of stocks in the analyst portfolios over the previous six months. "\# of analysts/stock" is the average number of analysts for each stock in the analyst portfolios. "\# of analysts employed/broker" is the average number of analysts employed by the brokerage firm to which the analyst is affiliated. Factor loadings represent the cross-sectional average coefficients of time-series analyst long and short excess portfolio returns regressed on the factors of the four-factor model. Details of the regression are provided in the caption for Table 3 .

\begin{tabular}{|c|c|c|c|c|c|c|c|c|c|c|}
\hline Portfolios & $\begin{array}{l}\text { Size } \\
\text { (\$ millions) }\end{array}$ & $\mathrm{P} / \mathrm{E}$ & $\begin{array}{l}\text { Sales } \\
\text { growth }\end{array}$ & Past \%return & $\begin{array}{l}\text { \# of analysts/ } \\
\text { stock }\end{array}$ & $\begin{array}{l}\text { \# of analysts } \\
\text { employed/broker }\end{array}$ & $\begin{array}{l}\text { Factor } \\
\text { loading exmkt }\end{array}$ & $\begin{array}{l}\text { Factor } \\
\text { loading } s m b\end{array}$ & $\begin{array}{l}\text { Factor } \\
\text { loading } \mathrm{hml}\end{array}$ & $\begin{array}{l}\text { Factor } \\
\text { loading mom }\end{array}$ \\
\hline \multicolumn{11}{|l|}{ Panel A: Long portfolios } \\
\hline F1 (MOST FREquent) & $10,006.38$ & 40.66 & 1.65 & 11.49 & 7.45 & 41.92 & 1.148 & 0.476 & 0.095 & -0.136 \\
\hline $\mathrm{F} 2$ & 8595.46 & 37.42 & 1.71 & 10.72 & 7.16 & 44.23 & 1.142 & 0.475 & 0.097 & -0.130 \\
\hline F3 & 8413.88 & 36.14 & 1.76 & 10.40 & 7.14 & 45.79 & 1.141 & 0.469 & 0.107 & -0.125 \\
\hline F4 & 8776.65 & 35.04 & 2.11 & 9.38 & 7.19 & 47.74 & 1.138 & 0.457 & 0.123 & -0.125 \\
\hline F5 (least frequent) & $10,130.75$ & 34.26 & 2.11 & 8.12 & 7.31 & 49.20 & 1.128 & 0.443 & 0.128 & -0.124 \\
\hline Overall & 9163.05 & 36.68 & 1.86 & 10.02 & 7.25 & 45.82 & & & & \\
\hline \multicolumn{11}{|l|}{ Panel B: Short portfolios } \\
\hline F1 (most frequent) & $11,089.80$ & 56.43 & 1.94 & 0.48 & 7.32 & 41.76 & 1.072 & 0.519 & 0.149 & -0.312 \\
\hline F2 & $10,064.06$ & 57.07 & 1.96 & 0.27 & 7.12 & 44.24 & 1.074 & 0.542 & 0.149 & -0.318 \\
\hline F3 & 9823.57 & 56.29 & 1.86 & 0.13 & 7.08 & 45.66 & 1.064 & 0.545 & 0.160 & -0.320 \\
\hline $\mathrm{F} 4$ & $10,641.96$ & 54.20 & 1.68 & 0.96 & 7.22 & 47.56 & 1.059 & 0.533 & 0.167 & -0.315 \\
\hline F5 (least frequent) & $12,132.76$ & 50.97 & 1.67 & 3.02 & 7.37 & 48.35 & 1.054 & 0.492 & 0.178 & -0.302 \\
\hline Overall & $10,766.12$ & 55.01 & 1.82 & 0.94 & 7.22 & 45.48 & & & & \\
\hline
\end{tabular}

portfolios of "infrequent" analysts load somewhat higher on $\mathrm{hml}$, indicating that these portfolios are likely to contain more value stocks.

It is also useful to compare the stocks for which the last revision was an upgrade (panel A of Table 2) to those that were last downgraded (panel B of Table 2). There are some clear differences between the two groups; for example, recently downgraded stocks tend to be somewhat larger and have higher P/E ratios. Past sales growth is similar for upgrades and downgrades - however, past returns for recently upgraded stocks are much higher. Overall, the average upgraded stock had a buy-and-hold return of $10.02 \%$ over the previous six months, while the buy-and-hold return for the average downgraded stock was less than $1 \%$. This large discrepancy between upgrades and downgrades exists across all quintiles and is consistent with a block of empirical research (e.g. Groth et al., 1979) suggesting that past performance significantly impacts recommendations. Compared to long portfolios, short portfolios are less sensitive to market movements, more sensitive to movements in the size (smb) and value ( $h m l$ ) premium and load more negatively on momentum.

\subsubsection{Profitability of analysts' recommendations}

Table 3 shows the average monthly excess returns to our long and short portfolios, with portfolios sorted into frequency-based quintiles. We compute the mean monthly excess return by benchmarking our portfolio against three models: the Capital Asset Pricing Model, the Fama-French three factor model (which includes excess market returns, firm size and book-to-market ratio), and the four-factor model (which includes the three factor model plus momentum). Panel A shows that the long portfolio's excess return is positive for all models but generally significant only when using the 4-factor model as the benchmark. More importantly, the highest excess returns can be found in the F1 quintile (analysts with most frequent revisions). The difference in excess returns between the first and fifth quintile (F1-F5) ranges from nearly $0.17 \%$ to $0.21 \%$ per month. Each of these numbers is significant at the $10 \%$ level. $^{7}$ This finding implies that the positive excess returns for sell-side stock analyst recommendations concentrate most heavily in the analysts who revise most frequently.

Panel B documents negative excess returns for most short portfolios. It is important to remember that the negative numbers depict the actual portfolio returns and not the returns to our investment strategy; by shorting these stocks the sign would be reversed (not accounting for transaction costs). Additionally, the largest negative returns reside in the first three quintiles, with the difference between the first and fifth quintiles significant at the $5 \%$ level under all three models. Although the absolute values of the returns are smaller than those of the long portfolio in each quintile, the difference between the extreme quintiles is much larger. Panel $\mathrm{C}$ shows the excess returns to the overall strategy of buying the recommendation upgrades and shorting the

\footnotetext{
7 Several studies e.g. Jegadeesh and Kim (2006) and Womack (1996) document that analyst recommendations are upwardly biased. At least some of this bias exists from the beginning (initiations), perhaps owing to the incentive bias of investment bank affiliated analysts toward firms accessing equity markets. Consistent with this, our results are stronger if we exclude initiations from our analysis.
} 
downgrades. All three models result in a highly significant mean excess monthly return for all but the fifth (lowest frequency) quintile. The highest excess returns are found in the first quintile and, if compounded, reach well over $6 \%$ annually. The difference between the excess returns to the first and fifth quintiles ranges from $0.46 \%$ to $0.48 \%$ and is significant at the $0.1 \%$ level. These findings suggest that all analysts but those with the least frequent revisions have valuable information. However, analysts who revise their recommendations most frequently generate the highest excess returns. This finding is consistent with the idea that analysts who issue recommendations more frequently bring more valuable and timely information to the market, either because they have superior access to producers of private information or because they process public information more efficiently. This finding complements the research of Yan and Zhang (2009), who show that the positive excess returns enjoyed by institutional investors are concentrated most heavily in short-term institutions.

\subsection{Robustness checks}

Although our findings indicate that investors can generate higher excess returns by following the recommendations of analysts with the most frequent revisions, it is possible that our results may be manifestations of other factors already known to help identify superior analyst recommendations. In this section we control for these alternative explanations and show that revision frequency indeed captures incremental information predicting the profitability of recommendations.

\subsubsection{Investment banking relationships}

Barber et al. (2007) argue that analysts employed by investment banks are reluctant to downgrade stocks of firms that are potential clients. As a result, the authors find that buy recommendations of analysts employed by independent research firms outperform those of analysts employed by investment banks. If analysts employed by investment banks tend to also revise less frequently, then it is possible that our result linking the frequency of revisions to profitability is just a manifestation of this. To investigate, we redo our analysis in Table 3 separately for analysts employed by investment banks and for other analysts.

We follow Barber et al. (2007) to categorize research providers into investment banks and into other (independent) research providers. In panel A of Table 4, we define investment banks as the 10 brokerage firms sanctioned in the Global Research Analyst Settlement of 2003, ${ }^{8}$ and all other providers are presumed not to be investment banks. The panel provides monthly excess returns of zero-investment portfolios formed by buying the upgrade portfolio and shorting the downgrade portfolio for each group of analysts sorted by revision frequency. Regardless of affiliation, analysts who frequently revise their recommendations outperform other analysts. For example, the difference in monthly excess return for the long-short portfolios of analysts between extreme frequency quintiles is around $0.75 \%(0.35 \%)$ for analysts associated with sanctioned banks (other research providers). These differences in monthly excess returns are statistically significant at the $5 \%$ level or better.

In panel B, investment banks are defined as brokerage houses that acted as lead, co-lead, or syndicate members in an equity issue during the sample period (as reported by the SDC database). The results in panel B are similar to those in panel A and demonstrate that frequently revising analysts tend to generate higher excess returns in both subsamples. The difference in mean longshort monthly excess returns between extreme analyst quintiles ranges from $0.377 \%$ to $0.694 \%$ and is significant at the $5 \%$ level in five out of six specifications. Overall, Table 4 suggests that our primary result holds regardless of whether analysts are employed by investment banks or by independent research providers. ${ }^{9}$

\subsubsection{Past recommendation profitability}

Li (2005), and Mikhail et al. (2004) report that analysts who have been relatively more successful at generating profitable recommendations in the past continue to do so in the future. This result suggests that some analysts have better access to private information, or alternatively, better skills to process public information. It is possible that analysts with these skills are the ones who are able to provide timelier recommendation revisions to investors. If so, our frequency measure may just be another manifestation of the performance persistence result.

To examine the robustness of our revision frequency measure to this possibility, in each month we classify analysts into two groups based on whether their prior 12 months' compounded abnormal returns were above or below the median. Abnormal returns are based on the CAPM, the Fama/French three factor model, and the Carhart four-factor model, respectively, as indicated in the column headers. Table 5 reports the results. Analysts with below median past performance provide more profitable recommendations when they revise more frequently. Specifically, the monthly excess return difference in the long-short portfolios of analysts between extreme frequency quintiles is around $0.65 \%$ and statistically significant. The relation between revision frequency and profitability is weaker among analysts with above median past performance - however, those with the least frequent recommendation revisions are the only group without a consistently positive abnormal return. Additionally, the results are stronger under the Carhart model than under the three-factor model. This indicates that since momentum is the only additional factor in the four-factor model, past returns may potentially explain the difference between these two models' results. In fact, the difference can be seen in Table 2, which shows the past returns of first quintile stocks to be $11.49 \%$ for upgrades and $0.48 \%$ for downgrades (an $11 \%$ difference) versus $8.12 \%$ for fifth-quintile upgrades and $3.02 \%$ for fifth-quintile downgrades (only a $5 \%$ difference).

\footnotetext{
${ }^{8}$ See http://www.sec.gov/spotlight/globalsettlement for details.

${ }^{9}$ We also separated brokerage firms who acted as lead and co-lead underwriters from those who merely acted as syndicate members. In unreported results we find that analysts with most frequent revisions earn the greatest excess returns for each subsample.
} 
Table 3

Profitability of recommendations. This table shows the percentage monthly mean abnormal return of the portfolios constructed using the analysts' upgrade (long), downgrade (short), and net (long minus short) portfolios. We assign the analysts to quintiles by sorting on the average length of their outstanding recommendations. In order to be included in the portfolio, each stock must have an outstanding recommendation issued within the last year. Upgraded (downgraded) stocks are added to the long (short) portfolios at the end of the recommendation days. Each added stock gets an equal one dollar of investment. The stock then stays in its assigned long or short portfolio until a subsequent upgrade or downgrade shifts it into the other. The stock also leaves the portfolio the day the analyst/brokerage house ceases to cover the stock or once it has remained in the portfolio for a year since the last upgrade (downgrade). Daily portfolio returns are compounded to compute monthly portfolio returns. In order to compute the monthly abnormal return of the portfolios, excess monthly portfolio returns are regressed on the excess market return for the CAPM, on the excess market, size, and book-to-market factors for the Fama-French model, and on the excess market, size, book-to-market, and momentum factors for the four-factor model, respectively. Excess market return, size, book-to-market, and momentum factors are downloaded from Kenneth French's website. The abnormal return in each month is the sum of the monthly residual and intercept from our regressions. P-values based on two-tailed t-tests are shown in parentheses. Panels A and B report the returns for the long and short portfolios, respectively, and Panel C reports the returns of the long-minus-short portfolios, which are essentially zero-investment portfolios formed by buying the upgrade portfolio and selling short the downgrade portfolio of each analyst.

\begin{tabular}{|c|c|c|c|}
\hline \multirow[t]{2}{*}{ Portfolios } & \multicolumn{3}{|c|}{ Mean monthly abnormal return (\%) (p-value) } \\
\hline & CAPM & Fama-French & Four factor \\
\hline \multicolumn{4}{|c|}{ Panel A: Long portfolios } \\
\hline F1 (most frequent) & $0.396(0.044)$ & $0.199(0.111)$ & $0.332(0.002)$ \\
\hline F2 & $0.232(0.215)$ & $0.082(0.460)$ & $0.199(0.039)$ \\
\hline F3 & $0.323(0.098)$ & $0.149(0.234)$ & $0.251(0.022)$ \\
\hline F4 & $0.193(0.301)$ & $0.062(0.613)$ & $0.184(0.091)$ \\
\hline F5 (least frequent) & $0.186(0.308)$ & $0.034(0.800)$ & $0.161(0.167)$ \\
\hline F1-F5 & $0.210(0.087)$ & $0.165(0.092)$ & $0.171(0.074)$ \\
\hline \multicolumn{4}{|c|}{ Panel B: Short portfolios } \\
\hline F1 (most frequent) & $-0.147(0.536)$ & $-0.389(0.040)$ & $-0.147(0.219)$ \\
\hline F2 & $-0.115(0.637)$ & $-0.321(0.086)$ & $-0.081(0.442)$ \\
\hline F3 & $-0.141(0.581)$ & $-0.381(0.043)$ & $-0.119(0.300)$ \\
\hline F4 & $-0.070(0.780)$ & $-0.260(0.160)$ & $-0.002(0.984)$ \\
\hline F5 (least frequent) & $0.125(0.575)$ & $-0.094(0.584)$ & $0.168(0.140)$ \\
\hline F1-F5 & $-0.272(0.032)$ & $-0.295(0.009)$ & $-0.314(0.004)$ \\
\hline \multicolumn{4}{|c|}{ Panel C: Long-short portfolios } \\
\hline F1 (most frequent) & $0.543(0.000)$ & $0.589(0.000)$ & $0.479(0.000)$ \\
\hline $\mathrm{F} 2$ & $0.348(0.025)$ & $0.403(0.007)$ & $0.280(0.010)$ \\
\hline F3 & $0.464(0.003)$ & $0.529(0.001)$ & $0.371(0.002)$ \\
\hline F4 & $0.263(0.080)$ & $0.322(0.027)$ & $0.186(0.110)$ \\
\hline F5 (least frequent) & $0.061(0.643)$ & $0.129(0.316)$ & $-0.006(0.951)$ \\
\hline F1-F5 & $0.481(0.001)$ & $0.460(0.001)$ & $0.485(0.000)$ \\
\hline
\end{tabular}

Thus, our finding on the association between recommendation frequency and profitability exists mainly for analysts with low past performance.

\subsubsection{Recommendations of star analysts}

Next, we inspect whether the status of the analyst - "star" versus "non-star" - impacts the excess returns that we documented in Table 3. Previous research has linked status or title to fees and compensation (e.g. Dorfman (1991), Galant (1992), and Stickel (1995)). Additionally, Fang and Yasuda (2011) and Loh and Stulz (2011) find evidence that status and experience are positively related to excess returns, while Emery and Li (2009) suggest that status may be negatively related to excess returns. To control for the analyst's status, we categorize our analysts as stars or non-stars and then sort on their revision frequency. We define a "star" analyst as one who appeared on the Institutional Investor's first, second, or third analyst all-star team. ${ }^{10}$ Panel B of Table 5 shows the results. We find that analysts with the highest frequency of revisions outperform those with the lowest frequency in both the star and non-star groups. The difference in abnormal returns between the first and fifth quintile is statistically significant for non-star analysts at the $1 \%$ level and for stars at the $10 \%$ level. Thus the status of the analyst does not appear to influence the excess returns from Table 3.

\subsubsection{Recommendations accompanied by earnings forecasts}

Kecskes et al. (2010) find that recommendation changes accompanied by confirming and "innovative" earnings forecast changes have approximately double the investment value of other recommendations. It is possible that earnings forecasts are provided with the timeliest recommendation changes, and thus our main finding could be a manifestation of Kecskes et al.'s (2010) result. In this section we focus on whether recommendations are accompanied by earnings forecasts. We separate into two groups the recommendation changes that occur within a day of (before or after) earnings forecast changes made by the

\footnotetext{
${ }^{10}$ We sincerely thank Michael Cliff of Virginia Tech who provided us with the data on star analysts.
} 


\section{Table 4}

Recommendations by analyst investment bank affiliation. This table shows the average percentage monthly mean abnormal return of portfolios constructed using the analysts' long minus short portfolios, in subsamples of whether or not the analyst is employed by an investment bank, and within that, in quintiles formed by sorting on the average length of the analyst's outstanding recommendations. Subsample assignments are updated each month. In Panel A, analysts affiliated with the 10 brokerage firms sanctioned in the Global Research Analyst Settlement of 2002 are considered analysts employed by an investment bank; all other analysts are assumed to be employed by other research providers. In Panel B analysts employed by brokerage firms that acted as lead, co-lead, or as a syndicate member on an equity issuance during the sample period (as recorded by SDC) are considered to be analysts employed by an investment bank; all other analysts are assumed to be employed by independent research firms. The calculation of abnormal returns for analyst long-short portfolios is described in the caption of Table 3. P-values based on two-tailed t-tests are in parentheses.

\begin{tabular}{|c|c|c|c|c|c|c|c|}
\hline \multicolumn{8}{|l|}{ Long-short portfolios } \\
\hline & \multirow[t]{2}{*}{ Portfolios } & \multicolumn{6}{|c|}{ Mean monthly abnormal return (\%) (p-value) } \\
\hline & & \multicolumn{2}{|l|}{ CAPM } & \multicolumn{2}{|c|}{ Fama-French } & \multicolumn{2}{|c|}{ Four factor } \\
\hline \multicolumn{8}{|c|}{ Panel A: Investment banks in the Global Research Analyst Settlement of 2002} \\
\hline \multirow[t]{6}{*}{ Other research providers } & F1 (most frequent) & 0.481 & $(0.006)$ & 0.520 & $(0.002)$ & 0.411 & $(0.001)$ \\
\hline & $\mathrm{F} 2$ & 0.356 & $(0.027)$ & 0.412 & $(0.007)$ & 0.301 & $(0.008)$ \\
\hline & F3 & 0.511 & $(0.002)$ & 0.567 & $(0.000)$ & 0.414 & $(0.001)$ \\
\hline & F4 & 0.291 & $(0.047)$ & 0.344 & $(0.017)$ & 0.213 & $(0.090)$ \\
\hline & F5 (least frequent) & 0.137 & $(0.376)$ & 0.182 & $(0.232)$ & 0.056 & $(0.664)$ \\
\hline & F1-F5 & 0.343 & $(0.048)$ & 0.337 & $(0.049)$ & 0.356 & $(0.038)$ \\
\hline \multirow[t]{6}{*}{10 Investment banks in settlement } & F1 (most frequent) & 0.690 & $(0.004)$ & 0.760 & $(0.001)$ & 0.657 & $(0.004)$ \\
\hline & F2 & 0.344 & $(0.100)$ & 0.390 & $(0.060)$ & 0.220 & $(0.188)$ \\
\hline & F3 & 0.298 & $(0.166)$ & 0.393 & $(0.059)$ & 0.218 & $(0.220)$ \\
\hline & $\mathrm{F} 4$ & 0.155 & $(0.525)$ & 0.232 & $(0.319)$ & 0.082 & $(0.656)$ \\
\hline & F5 (least frequent) & -0.088 & $(0.625)$ & 0.021 & $(0.902)$ & -0.123 & $(0.443)$ \\
\hline & F1-F5 & 0.777 & $(0.003)$ & 0.739 & $(0.007)$ & 0.780 & $(0.004)$ \\
\hline \multicolumn{8}{|c|}{ Panel B: Investment banks in equity issue syndicates } \\
\hline \multirow[t]{6}{*}{ Independent research firms } & F1 (most frequent) & 0.738 & $(0.002)$ & 0.796 & $(0.000)$ & 0.657 & $(0.001)$ \\
\hline & $\mathrm{F} 2$ & 0.137 & $(0.536)$ & 0.207 & $(0.322)$ & 0.082 & $(0.617)$ \\
\hline & F3 & 0.374 & $(0.065)$ & 0.472 & $(0.015)$ & 0.304 & $(0.096)$ \\
\hline & $\mathrm{F} 4$ & 0.341 & $(0.118)$ & 0.384 & $(0.081)$ & 0.234 & $(0.255)$ \\
\hline & F5 (least frequent) & 0.225 & $(0.383)$ & 0.150 & $(0.552)$ & -0.037 & $(0.872)$ \\
\hline & F1-F5 & 0.513 & $(0.074)$ & 0.647 & $(0.029)$ & 0.694 & $(0.020)$ \\
\hline \multirow[t]{6}{*}{ Investment banks } & F1 (most frequent) & 0.445 & $(0.005)$ & 0.493 & $(0.001)$ & 0.399 & $(0.002)$ \\
\hline & $\mathrm{F} 2$ & 0.424 & $(0.007)$ & 0.479 & $(0.002)$ & 0.357 & $(0.002)$ \\
\hline & F3 & 0.498 & $(0.003)$ & 0.554 & $(0.001)$ & 0.394 & $(0.001)$ \\
\hline & $\mathrm{F} 4$ & 0.258 & $(0.095)$ & 0.318 & $(0.032)$ & 0.181 & $(0.127)$ \\
\hline & F5 (least frequent) & 0.010 & $(0.940)$ & 0.116 & $(0.357)$ & -0.003 & $(0.976)$ \\
\hline & F1-F5 & 0.435 & $(0.006)$ & 0.377 & $(0.013)$ & 0.402 & $(0.007)$ \\
\hline
\end{tabular}

same analyst for the same firm and those that do not. Table 6 provides mean monthly excess returns for zero-investment longshort portfolios constructed within these two groups. We observe that in most cases analysts with more frequent recommendation changes outperform analysts who revise less frequently; furthermore, this difference is economically larger and statistically significant among recommendations without earnings forecasts. Thus it appears that revision frequency predicts success incremental to that which is predicted by earnings forecasts.

\subsubsection{Experience of analysts}

Several papers find that experienced analysts issue more profitable recommendations (e.g. Fang and Yasuda, 2011; Loh and Stulz, 2011). It is possible that analysts with more experience revise their recommendations more frequently, and if so, then our result could just be a manifestation of analyst experience. Therefore, we examine to what extent our results are influenced by differences in analysts' experience. Following Loh and Stulz (2011), we measure analyst experience as the number of quarters since the analyst issued the first earnings forecast or stock recommendation on IBES. We use the earlier of two dates if the analyst issues both forecasts and recommendations. We classify analysts into two groups based on above median and below median experience in every month of our sample period. The results in panel A of Table 7 indicate that the mean excess returns of longshort portfolios within both experienced and non-experienced analysts is greater for analysts with the most frequent recommendation revisions compared to analysts with the least frequent revisions. However, the results are statistically significant only for analysts with above median experience. A possible explanation is that more experienced analysts are less affected by career concerns and therefore are able to provide "bolder" recommendations in addition to the "bolder" forecasts documented in the literature.

Revision frequency is an especially salient predictor of profitability when one examines the difference between experienced and inexperienced analysts within the same quintile. Panel A shows the average abnormal return for experienced, highestfrequency analysts to be $0.716 \%$ under the CAPM versus $0.365 \%$ for inexperienced, highest-frequency analysts. This is greater than the difference within any other quintile, regardless of which abnormal return model we use. Thus it appears that some of the difference in profitability between experienced and inexperienced analysts is captured in the frequency of revisions. 
Table 5

Recommendations by analysts' past recommendation profitability and by analyst star status. This table provides monthly mean abnormal returns of portfolios constructed using the analysts' long minus short portfolios. Panel A presents subsamples of analysts' past recommendation performance, and within that, quintiles sorted by the average length of the analyst's outstanding recommendations. We classify analysts into two groups of above and below median past performance on the basis of the analyst's prior 12 months long-short portfolio buy-and-hold abnormal return benchmarked with the CAPM, the Fama-French three factor, and the four-factor models, respectively. Panel B presents subsamples based on analyst star status and within that, quintiles sorted by the average length of the analyst's outstanding recommendations. The analyst is designated a "star" if in the previous year the analyst appeared on the Institutional Investor's all-star analyst team (first-, second-, or third-team). Subsample assignments are updated in each month. The calculation of abnormal returns for analyst long-short portfolios is described in the caption of Table 3. P-values based on two-tailed t-tests are in parentheses.

\begin{tabular}{|c|c|c|c|c|c|c|c|}
\hline \multicolumn{8}{|l|}{ Long-short portfolios } \\
\hline & \multirow[t]{2}{*}{ Portfolios } & \multicolumn{6}{|c|}{ Mean monthly abnormal return (\%) (p-value) } \\
\hline & & \multicolumn{2}{|l|}{ CAPM } & \multicolumn{2}{|c|}{ Fama-French } & \multicolumn{2}{|c|}{ Four Factor } \\
\hline \multicolumn{8}{|l|}{ Panel A: Past recommendation profitability } \\
\hline \multirow[t]{6}{*}{ Analysts with below median past 12 month recommendation profitability } & F1 (most frequent) & 0.705 & $(0.000)$ & 0.728 & $(0.000)$ & 0.549 & $(0.001)$ \\
\hline & F2 & 0.620 & $(0.001)$ & 0.651 & $(0.000)$ & 0.439 & $(0.006)$ \\
\hline & F3 & 0.547 & $(0.031)$ & 0.725 & $(0.000)$ & 0.474 & $(0.019)$ \\
\hline & F4 & 0.446 & $(0.009)$ & 0.542 & $(0.001)$ & 0.239 & $(0.207)$ \\
\hline & F5 (least frequent) & 0.046 & $(0.800)$ & 0.086 & $(0.632)$ & -0.187 & $(0.348)$ \\
\hline & F1-F5 & 0.658 & $(0.004)$ & 0.641 & $(0.005)$ & 0.736 & $(0.001)$ \\
\hline \multirow[t]{6}{*}{ Analysts with above median past 12 month recommendation profitability } & F1 (most frequent) & 0.322 & $(0.080)$ & 0.494 & $(0.001)$ & 0.439 & $(0.003)$ \\
\hline & $\mathrm{F} 2$ & 0.307 & $(0.104)$ & 0.490 & $(0.004)$ & 0.395 & $(0.002)$ \\
\hline & F3 & 0.638 & $(0.001)$ & 0.551 & $(0.001)$ & 0.488 & $(0.001)$ \\
\hline & F4 & 0.485 & $(0.007)$ & 0.574 & $(0.001)$ & 0.500 & $(0.001)$ \\
\hline & F5 (Least Frequent) & -0.031 & $(0.872)$ & 0.138 & $(0.464)$ & -0.077 & $(0.649)$ \\
\hline & F1-F5 & 0.353 & $(0.158)$ & 0.356 & $(0.121)$ & 0.516 & $(0.018)$ \\
\hline \multicolumn{8}{|l|}{ Panel B: Analyst "star" status } \\
\hline \multirow[t]{6}{*}{ Non-star analysts } & F1 (most frequent) & 0.530 & $(0.001)$ & 0.558 & $(0.000)$ & 0.449 & $(0.000)$ \\
\hline & F2 & 0.386 & $(0.018)$ & 0.430 & $(0.006)$ & 0.318 & $(0.007)$ \\
\hline & F3 & 0.477 & $(0.005)$ & 0.553 & $(0.001)$ & 0.390 & $(0.003)$ \\
\hline & F4 & 0.313 & $(0.055)$ & 0.363 & $(0.023)$ & 0.228 & $(0.080)$ \\
\hline & F5 (least frequent) & 0.036 & $(0.810)$ & 0.083 & $(0.568)$ & -0.045 & $(0.716)$ \\
\hline & F1-F5 & 0.493 & $(0.003)$ & 0.475 & $(0.004)$ & 0.494 & $(0.002)$ \\
\hline \multirow[t]{6}{*}{ Star analysts } & F1 (most frequent) & 0.555 & $(0.010)$ & 0.678 & $(0.001)$ & 0.564 & $(0.003)$ \\
\hline & $\mathrm{F} 2$ & 0.183 & $(0.355)$ & 0.280 & $(0.159)$ & 0.111 & $(0.502)$ \\
\hline & F3 & 0.412 & $(0.033)$ & 0.454 & $(0.016)$ & 0.322 & $(0.055)$ \\
\hline & F4 & 0.087 & $(0.651)$ & 0.189 & $(0.304)$ & 0.055 & $(0.741)$ \\
\hline & F5 (least frequent) & 0.121 & $(0.505)$ & 0.258 & $(0.154)$ & 0.101 & $(0.534)$ \\
\hline & F1-F5 & 0.435 & $(0.082)$ & 0.420 & $(0.086)$ & 0.463 & $(0.055)$ \\
\hline
\end{tabular}

\subsubsection{Number of stocks covered by analysts}

Finally, it is possible that the analysts in our first quintile change stock recommendations more frequently simply because they have fewer stocks to cover and can therefore devote a greater percentage of their time to uncovering more valuable information for each stock. To examine this possibility in greater detail, we sort analysts into two groups by the number of stocks covered and then within each group we further sort them by the frequency of recommendation changes. Panel B of Table 7 provides the results. We find that regardless of how many stocks the analyst covers, those analysts with the most frequent revisions significantly outperform the analysts with the least frequent recommendation changes. Thus, it appears that the significant excess returns we observed in Table 3 are not driven by the fact that some analysts cover more stocks than others.

\section{Sources of higher profitability for frequently revising analysts}

\subsection{Overview}

Thus far, we have found that the frequency of revision relates positively to profitability and, with the exception of analyst experience, is robust to a host of other factors that have previously been shown to affect profitability. ${ }^{11}$ We now explore a few of the potential reasons for why the most frequently revising analysts enjoy this advantage.

First, analysts who revise their recommendations frequently may be better at processing publicly available information than those who revise infrequently. To explore this, we examine analyst behavior surrounding firms' earnings announcements. Second, frequently revising analysts may be better at uncovering non-public information or interpreting information that is a bit more obscure than earnings announcements. To explore this, we document other types of "information events", proxied by large moves in the stock price or high trading volume. Third, frequently revising analysts may yield higher returns to their investors simply because they make more revisions; infrequently revising analysts may give advice that, per recommendation, yields as

\footnotetext{
${ }^{11}$ Even among relatively inexperienced analysts, those who revise most frequently outperform those who revise least frequently, though the difference is statistically weak.
} 
Table 6

Recommendations accompanied by earnings forecast revisions. This table provides monthly mean abnormal returns of portfolios constructed using the analysts' long minus short portfolios. The subsamples are based on whether or not a recommendation change is accompanied by an earnings forecast, and within those groups, quintiles are sorted by the average length of the analyst's outstanding recommendations. A recommendation change is defined to be accompanied by an earnings forecast if the recommendation change is made in the three trading days centered on an earnings forecast made by the same analyst for the same firm. P-values based on two-tailed t-tests are in parentheses.

\begin{tabular}{|c|c|c|c|c|c|c|c|}
\hline \multicolumn{8}{|l|}{ Recommendations accompanied by earnings forecasts } \\
\hline \multicolumn{8}{|l|}{ Long-short portfolios } \\
\hline & \multirow[t]{2}{*}{ Portfolios } & \multicolumn{6}{|c|}{ Mean monthly abnormal return (\%) (p-value) } \\
\hline & & \multicolumn{2}{|l|}{ CAPM } & \multicolumn{2}{|c|}{ Fama-French } & \multicolumn{2}{|c|}{ Four factor } \\
\hline \multirow[t]{6}{*}{ Recommendations without earnings forecast revisions } & F1 (most frequent) & 0.675 & $(0.000)$ & 0.465 & $(0.020)$ & 0.428 & $(0.025)$ \\
\hline & $\mathrm{F} 2$ & 0.192 & $(0.222)$ & 0.273 & $(0.071)$ & 0.224 & $(0.085)$ \\
\hline & F3 & 0.303 & $(0.105)$ & 0.442 & $(0.012)$ & 0.340 & $(0.027)$ \\
\hline & F4 & 0.290 & $(0.085)$ & 0.248 & $(0.104)$ & 0.200 & $(0.157)$ \\
\hline & F5 (least frequent) & -0.032 & $(0.843)$ & 0.041 & $(0.788)$ & -0.086 & $(0.560)$ \\
\hline & F1-F5 & 0.708 & $(0.001)$ & 0.424 & $(0.071)$ & 0.514 & $(0.028)$ \\
\hline \multirow[t]{6}{*}{ Recommendations made in conjunction with earnings forecast revisions } & F1 (most frequent) & 0.465 & $(0.041)$ & 0.583 & $(0.005)$ & 0.449 & $(0.004)$ \\
\hline & F2 & 0.537 & $(0.006)$ & 0.566 & $(0.002)$ & 0.382 & $(0.010)$ \\
\hline & F3 & 0.540 & $(0.004)$ & 0.578 & $(0.002)$ & 0.453 & $(0.002)$ \\
\hline & F4 & 0.227 & $(0.235)$ & 0.304 & $(0.087)$ & 0.142 & $(0.350)$ \\
\hline & F5 (least frequent) & 0.215 & $(0.240)$ & 0.314 & $(0.072)$ & 0.097 & $(0.529)$ \\
\hline & F1-F5 & 0.250 & $(0.221)$ & 0.268 & $(0.173)$ & 0.352 & $(0.066)$ \\
\hline
\end{tabular}

Table 7

Recommendations by analyst experience and by the number of stocks covered. This table provides monthly mean abnormal returns of portfolios constructed using the analysts' long minus short portfolios. Panel A presents subsamples of analyst experience, and within that, quintiles sorted by the average length of the analyst's outstanding recommendations. An analyst is considered experienced if the number of quarters since the analyst issued his first earnings forecast or stock recommendation on IBES is above the median for all analysts. We use the earlier of two dates if the analyst issues both forecasts and recommendations. Panel B presents two subsamples formed by the number of stocks covered by the analyst, and within that, quintiles formed by sorting on the average length of the analyst's outstanding recommendations. Subsample assignments are updated in each month. The calculation of abnormal returns for analyst long-short portfolios is described in the caption of Table 3. P-values based on two-tailed t-tests are in parentheses.

\begin{tabular}{|c|c|c|c|c|c|c|c|}
\hline \multicolumn{8}{|l|}{ Panel A: Analyst experience } \\
\hline \multicolumn{8}{|l|}{ Long-short portfolios } \\
\hline & \multirow[t]{2}{*}{ Portfolios } & \multicolumn{6}{|c|}{ Mean monthly abnormal return (\%) (p-value) } \\
\hline & & \multicolumn{2}{|l|}{ CAPM } & \multicolumn{2}{|c|}{ Fama-French } & \multicolumn{2}{|c|}{ Four factor } \\
\hline \multirow{6}{*}{ Analysts with below median experience } & F1 (most frequent) & 0.365 & $(0.071)$ & 0.423 & $(0.025)$ & 0.288 & $(0.066)$ \\
\hline & $\mathrm{F} 2$ & 0.315 & $(0.170)$ & 0.363 & $(0.098)$ & 0.279 & $(0.065)$ \\
\hline & F3 & 0.460 & $(0.014)$ & 0.526 & $(0.004)$ & 0.344 & $(0.017)$ \\
\hline & F4 & 0.096 & $(0.610)$ & 0.179 & $(0.317)$ & 0.007 & $(0.961)$ \\
\hline & F5 (least frequent) & 0.029 & $(0.881)$ & 0.098 & $(0.586)$ & -0.034 & $(0.839)$ \\
\hline & F1-F5 & 0.336 & $(0.138)$ & 0.325 & $(0.113)$ & 0.322 & $(0.119)$ \\
\hline \multirow[t]{6}{*}{ Analysts with above median experience } & F1 (most frequent) & 0.716 & $(0.000)$ & 0.761 & $(0.000)$ & 0.668 & $(0.000)$ \\
\hline & $\mathrm{F} 2$ & 0.361 & $(0.011)$ & 0.421 & $(0.003)$ & 0.258 & $(0.039)$ \\
\hline & F3 & 0.444 & $(0.008)$ & 0.510 & $(0.002)$ & 0.373 & $(0.008)$ \\
\hline & F4 & 0.411 & $(0.008)$ & 0.446 & $(0.004)$ & 0.350 & $(0.009)$ \\
\hline & F5 (least frequent) & 0.100 & $(0.488)$ & 0.177 & $(0.225)$ & 0.038 & $(0.763)$ \\
\hline & F1-F5 & 0.616 & $(0.001)$ & 0.584 & $(0.002)$ & 0.630 & $(0.001)$ \\
\hline \multicolumn{8}{|l|}{ Panel B: Number of stocks covered by the analyst } \\
\hline \multicolumn{8}{|l|}{ Long-short portfolios } \\
\hline \multirow[t]{2}{*}{ \# of stocks covered } & Portfolios & \multicolumn{6}{|c|}{ Mean monthly abnormal return (\%) (p-value) } \\
\hline & & \multicolumn{2}{|l|}{ CAPM } & \multicolumn{2}{|c|}{ Fama-French } & \multicolumn{2}{|c|}{ Four factor } \\
\hline \multirow[t]{6}{*}{ Below median number of stocks covered by analyst } & F1 (most frequent) & 0.548 & $(0.004)$ & 0.640 & $(0.000)$ & 0.537 & $(0.000)$ \\
\hline & F2 & 0.224 & $(0.273)$ & 0.238 & $(0.232)$ & 0.166 & $(0.295)$ \\
\hline & F3 & 0.460 & $(0.027)$ & 0.516 & $(0.011)$ & 0.375 & $(0.032)$ \\
\hline & F4 & 0.346 & $(0.055)$ & 0.411 & $(0.018)$ & 0.264 & $(0.097)$ \\
\hline & F5 (least frequent) & 0.046 & $(0.744)$ & 0.096 & $(0.481)$ & -0.035 & $(0.778)$ \\
\hline & F1-F5 & 0.502 & $(0.011)$ & 0.545 & $(0.004)$ & 0.572 & $(0.003)$ \\
\hline \multirow[t]{6}{*}{ Above median number of stocks covered by analyst } & F1 (most frequent) & 0.533 & $(0.001)$ & 0.521 & $(0.000)$ & 0.411 & $(0.001)$ \\
\hline & $\mathrm{F} 2$ & 0.404 & $(0.011)$ & 0.495 & $(0.001)$ & 0.344 & $(0.003)$ \\
\hline & F3 & 0.486 & $(0.003)$ & 0.564 & $(0.000)$ & 0.393 & $(0.002)$ \\
\hline & F4 & 0.178 & $(0.281)$ & 0.239 & $(0.143)$ & 0.113 & $(0.360)$ \\
\hline & F5 (least frequent) & 0.110 & $(0.610)$ & 0.203 & $(0.340)$ & 0.055 & $(0.752)$ \\
\hline & F1-F5 & 0.423 & $(0.016)$ & 0.318 & $(0.078)$ & 0.356 & $(0.038)$ \\
\hline
\end{tabular}


much or perhaps more profit in the short-term, but the rarity of revisions causes the returns to be lower over the course of a year (recall that our portfolios drop a stock only after its most recent recommendation has been outstanding for a full year). To explore this, we shorten each stock investment in our portfolios to a maximum of two months.

\subsubsection{Earnings announcements}

If frequently revising analysts process public information more accurately or more quickly than do infrequently revising analysts, then one would expect such a skill to show up around specific, public events such as earnings announcements. Table 8 explores this possibility. In panel A, the proportion of earnings announcement period recommendations (Days -1 through +1 ) versus nonearnings announcement period recommendations are shown for each analyst quintile. Though unreported, the difference between the first and fifth quintile is statistically insignificant. Thus, even though analysts in the first quintile by definition make more revisions than do analysts in the fifth quintile, if their primary advantage revolved around public information then one would have expected a significantly higher percentage of their revisions to occur around earnings announcements than the revisions of fifth quintile analysts.

However, it is also possible that even though first-quintile analysts make the same fraction of their revisions around earnings announcements as their less frequently revising counterparts, they do so with greater accuracy. If this is the case, then one would expect at least a portion of their excess return advantage to concentrate in this specific subset of revisions. Panel B of Table 8 compares the profitability across quintiles for both announcement period and non-announcement period recommendations. When we calculate excess returns using the CAPM, the difference between the first and fifth quintiles' profitability is larger for announcement-period revisions, but is also significant for non-announcement period revisions. When we use the three- or four-factor model instead, the first quintile's advantage concentrates completely in the subset of non-announcement period revisions. On balance, the higher profits generated by first-quintile analysts' recommendations do not appear to come from earnings announcements made by the firms that they cover. In fact, it may be argued that the frequently revising analysts' profitability stems from uncovering information that extends beyond public events such as earnings announcements.

\subsubsection{Abnormal price changes and trading volume}

It is possible that frequently revising analysts are better at interpreting certain forms of market behavior than they are at interpreting more public, firm-led events such as earnings announcements. Following Barber and Odean (2008), Conrad et al. (2005), and Da et al. (2011) Ryan and Taffler (2004), we proxy for other types of "information events" with stock price movements of larger than positive or negative $5 \%$ or greater than twice the normal daily trading volume.

\section{Table 8}

Earning announcements. This table shows the percentage of recommendation changes that occur around firms' earnings announcements, as well as the profitability of those recommendation changes, for all revision-frequency based analyst quintiles. Panel A presents the percentage of revisions that occur during the announcement period (Days -1 through +1 ) versus outside that period for each analyst quintile. Panel B presents subsamples based on whether a recommendation change is made in the three trading days centered on a firm earnings announcement, and within that, in quintiles formed by sorting on the average length of the analyst's outstanding recommendations. Subsample assignments are updated in each month. The calculation of abnormal returns for analyst long-short portfolios is described in the caption of Table 3. P-values based on two-tailed t-tests are in parentheses.

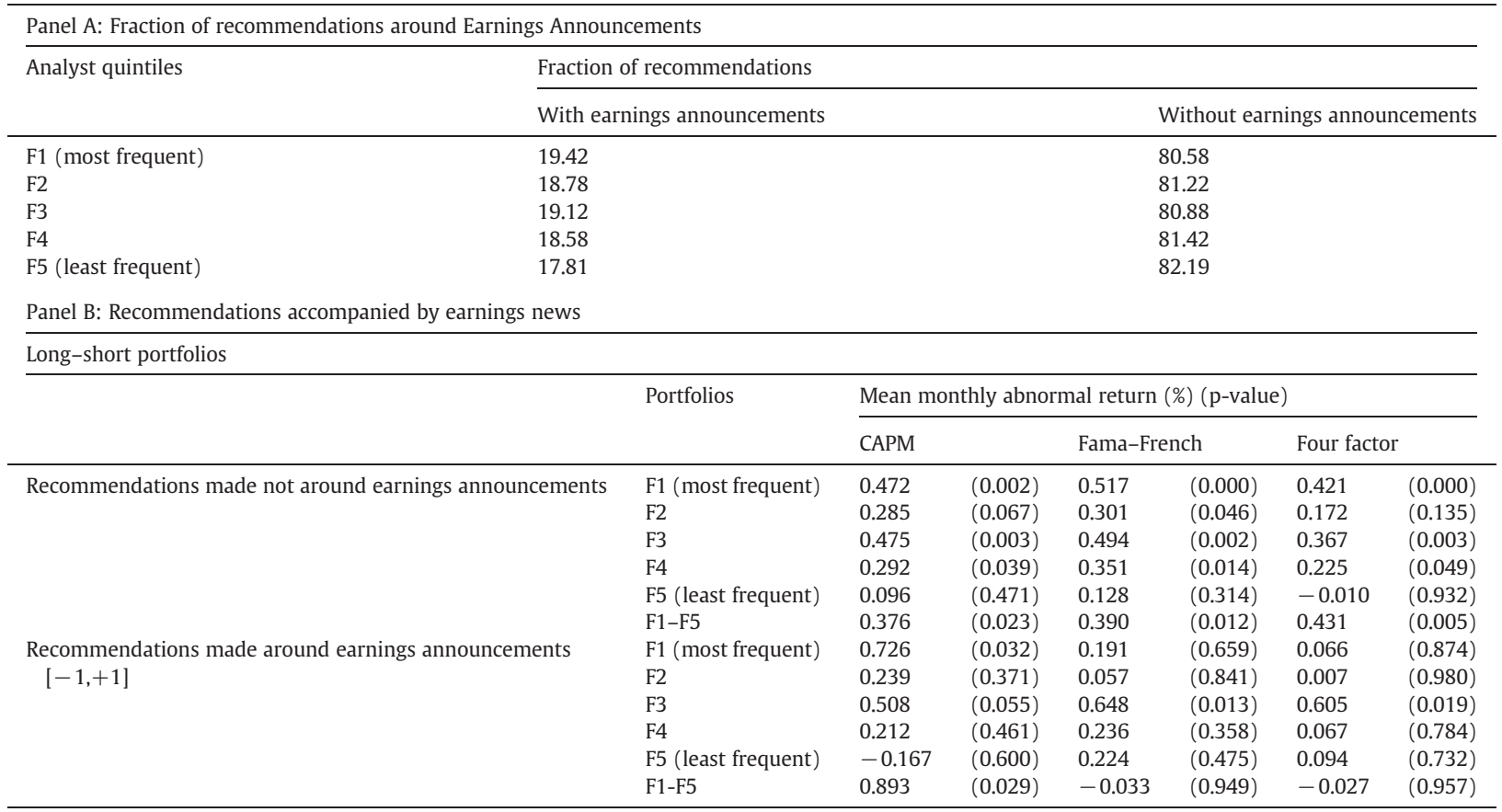


Panel A of Table 9 shows the average number of days that it takes each analyst quintile to make a recommendation change following an information event. For the overall sample as well as the subsamples of upgrades and downgrades, the difference in reaction time to large price changes (the columns on the left) between the first and fifth quintiles is significant. The columns on the right show a smaller, but still highly significant, difference in reaction time to days of abnormally high volume. Thus for both types of events, it is the frequently revising analysts who are the fastest to revise their recommendations.

Panel B compares the profitability of revisions following information events to that of other revisions. When the event is a large price change, revisions made by first quintile analysts yield abnormal returns of $0.38 \%$ (CAPM) to $0.60 \%$ (four-factor model) higher than those made by fifth-quintile analysts. Non-event revisions made by first-quintile analysts yield only $0.16 \%$ (Fama-French) to $0.24 \%$ (CAPM) higher than those made by fifth-quintile analysts. Following days of abnormally high trading, the first-quintile's advantage ranges from $0.40 \%$ to $0.45 \%$ versus only $0.11 \%$ to $0.18 \%$ for other recommendations. On the whole, we find that although the difference in profitability between first- and fifth-quintile analysts is sometimes marginally significant and always positive on days not following news events, it is (relatively) $50 \%$ to $250 \%$ higher and generally significant on days following news events. Thus we conclude that although Table 8 showed a highly public event (earnings announcements) to not be a significant source of frequently revising analysts' profitability, Table 9 suggests that much of their advantage does derive from reacting quickly to abnormal trading activity.

Table 9

Price and volume as proxies for news events. Panel A of this table shows the average number of days, for each quintile, between a "news event" and a recommendation change. Panel B shows the average abnormal returns across quintiles for those recommendations that occur after news events as well as for those that do not occur after news events. The calculation of abnormal returns is described in the caption of Table 3. P-values based on two-tailed t-tests are in parentheses.

\begin{tabular}{|c|c|c|c|c|c|c|}
\hline \multirow[t]{3}{*}{ Quintile } & \multicolumn{6}{|c|}{ Panel A: Average days to recommendation change } \\
\hline & \multicolumn{3}{|c|}{ News events proxied by $5 \%$ price change } & \multicolumn{3}{|c|}{ News event proxied by $200 \%$ turnover } \\
\hline & All rec's & Upgrade & Downgrades & All rec's & Upgrade & Downgrades \\
\hline F1 & 13.45 & 13.76 & 13.19 & 11.67 & 11.83 & 11.54 \\
\hline F2 & 14.44 & 14.98 & 14.01 & 12.92 & 13.17 & 12.72 \\
\hline F3 & 14.38 & 13.73 & 14.87 & 12.48 & 12.64 & 12.35 \\
\hline F4 & 14.99 & 16.50 & 13.92 & 13.52 & 13.53 & 13.51 \\
\hline F5 & 18.15 & 20.25 & 16.64 & 15.49 & 15.33 & 15.60 \\
\hline F5-F1 & $4.70^{* * *}$ & $5.49^{* * *}$ & $3.45^{* * *}$ & $3.82^{* * *}$ & $3.50^{* * *}$ & $4.06^{* * *}$ \\
\hline
\end{tabular}

\begin{tabular}{|c|c|c|c|c|c|c|c|}
\hline \multirow[b]{3}{*}{ Recommendations made after the major news event } & \multirow{3}{*}{$\begin{array}{l}\text { Portfolios } \\
\text { F1 (most frequent) }\end{array}$} & \multicolumn{6}{|c|}{ Mean monthly abnormal return (\%) (p-value) } \\
\hline & & \multicolumn{2}{|l|}{ CAPM } & \multicolumn{2}{|c|}{ Fama-French } & \multicolumn{2}{|c|}{ Four factor } \\
\hline & & 0.705 & $(0.001)$ & 0.647 & $(0.008)$ & 0.592 & $(0.008)$ \\
\hline & F2 & -0.078 & $(0.754)$ & -0.173 & $(0.510)$ & -0.240 & $(0.332)$ \\
\hline & F3 & 0.400 & $(0.069)$ & 0.394 & $(0.076)$ & 0.214 & $(0.310)$ \\
\hline & F4 & 0.521 & $(0.035)$ & 0.394 & $(0.083)$ & 0.276 & $(0.245)$ \\
\hline & F5 (least frequent) & 0.324 & $(0.179)$ & 0.227 & $(0.348)$ & -0.010 & $(0.966)$ \\
\hline & F1-F5 & 0.381 & $(0.101)$ & 0.420 & $(0.095)$ & 0.602 & $(0.062)$ \\
\hline Recommendations made NOT after major news & F1 (most frequent) & 0.240 & $(0.212)$ & 0.250 & $(0.138)$ & 0.188 & $(0.168)$ \\
\hline & $\mathrm{F} 2$ & 0.192 & $(0.285)$ & 0.236 & $(0.158)$ & 0.141 & $(0.275)$ \\
\hline & F3 & 0.093 & $(0.594)$ & 0.122 & $(0.468)$ & -0.013 & $(0.923)$ \\
\hline & F4 & 0.028 & $(0.859)$ & 0.081 & $(0.606)$ & -0.034 & $(0.800)$ \\
\hline & F5 (least frequent) & -0.002 & $(0.986)$ & 0.092 & $(0.510)$ & -0.038 & $(0.758)$ \\
\hline & F1-F5 & 0.242 & $(0.091)$ & 0.1607 & $(0.161)$ & 0.226 & $(0.067)$ \\
\hline \multicolumn{8}{|c|}{ Panel B: Long-short portfolios with news events news event proxied by $200 \%$ turnover } \\
\hline \multirow[t]{6}{*}{ Recommendations made after the major news event } & F1 (most frequent) & 0.566 & $(0.004)$ & 0.619 & $(0.001)$ & 0.554 & $(0.002)$ \\
\hline & F2 & -0.068 & $(0.737)$ & -0.088 & $(0.689)$ & -0.086 & $(0.685)$ \\
\hline & F3 & 0.383 & $(0.048)$ & 0.474 & $(0.010)$ & 0.378 & $(0.030)$ \\
\hline & F4 & 0.428 & $(0.040)$ & 0.405 & $(0.057)$ & 0.318 & $(0.120)$ \\
\hline & F5 (least frequent) & 0.112 & $(0.593)$ & 0.221 & $(0.277)$ & 0.157 & $(0.395)$ \\
\hline & F1-F5 & 0.454 & $(0.030)$ & 0.398 & $(0.039)$ & 0.397 & $(0.034)$ \\
\hline \multirow[t]{6}{*}{ Recommendations made NOT after major news } & F1 (most frequent) & 0.260 & $(0.071)$ & 0.266 & $(0.054)$ & 0.107 & $(0.213)$ \\
\hline & $\mathrm{F} 2$ & 0.306 & $(0.080)$ & 0.348 & $(0.032)$ & 0.244 & $(0.042)$ \\
\hline & F3 & 0.214 & $(0.202)$ & 0.255 & $(0.121)$ & 0.082 & $(0.546)$ \\
\hline & $\mathrm{F} 4$ & -0.038 & $(0.821)$ & -0.019 & $(0.906)$ & -0.196 & $(0.148)$ \\
\hline & F5 (least frequent) & 0.078 & $(0.601)$ & 0.153 & $(0.314)$ & -0.005 & $(0.961)$ \\
\hline & F1-F5 & 0.182 & $(0.119)$ & 0.113 & $(0.223)$ & 0.112 & $(0.274)$ \\
\hline
\end{tabular}

\footnotetext{
* Denotes significance at the $10 \%$ level.

** Denotes significance at the $5 \%$ level.

*** Denotes significance at the $1 \%$ level.
} 


\subsubsection{Revision frequency and long-run versus short-run profitability}

Although our results from Table 3 run counter to the hypothesis that infrequently revising analysts' information is longer-term than that of frequently revising analysts (at least insofar as we find that frequently revising analysts do better over the long-term), it is possible that the first quintile's profit advantage is a simple story of quantity over quality. In other words, it may be the case that the individual recommendations made by fifth-quintile analysts are on average equal to or even more profitable than those made by first-quintile analysts, but that the relative lack of revisions in the fifth-quintile portfolio causes it to have lower abnormal returns over the long-run. To explore this possibility, we keep the same analyst quintile designations as before, but redefine the portfolios such that we omit all recommendations outstanding for more than two months rather than one year.

The results of this alternative method of portfolio construction, shown in Table 10, are very similar to those in Table 3 . The difference between the first and fifth quintiles is positive and highly significant no matter which model we use to calculate abnormal returns, and the magnitude of that difference is actually greater for the three- and four-factor models in Table 10 (although the p-values are slightly larger) than in Table 3 . Thus it appears that even on a per-recommendation basis, the recommendations of frequently revising analysts are more profitable than those of infrequently revising analysts for a period of up to two months. We interpret this finding as evidence that the ordinary investor is better off following the advice of first-quintile analysts even over short periods of time. We find no evidence that whatever caution is exhibited by infrequently revising analysts leads to higher returns in either the short- or long-run.

\section{Discussion and conclusions}

Several studies document that the positive excess return subsequent to analyst recommendations (e.g. Dimson and Marsh (1984), Logue and Tuttle (1973), and Womack (1996)) is driven by analysts with certain characteristics. Consistent with the empirical literature, we find positive "alphas" subsequent to analyst recommendations, but we also find that the analysts who most frequently change their recommendations are the ones with the highest excess returns. We conduct several robustness tests and show that our results are not subsumed by characteristics that are known to predict performance, such as analyst independence, experience, star status, past profitability, the number of stocks covered, or whether a recommendation is accompanied by an earnings forecast. Thus it appears that analysts in our first quintile are simply able to identify mispriced stocks more often. These robustness results suggest that the frequency of recommendation revisions captures incremental information ignored by current factors known to help identify superior analyst recommendations.

Additionally, we conduct further analysis to explore the source of frequently revising analysts' abnormal return advantage. We find that most, if not all, of this advantage is concentrated in recommendations that do not occur after earnings announcements. We then look to see whether frequently revising analysts respond more quickly to other types of information events proxied by large stock price changes and trading volume. We find that first-quintile analysts not only are significantly quicker to respond to

Table 10

Short horizon portfolios. This table shows the percentage monthly mean abnormal return of the portfolios constructed using the analysts' upgrade (long), downgrade (short), and net (long minus short) portfolios. We assign the analysts to quintiles by sorting on the average length of their outstanding recommendations. This table is recast from Table 3 with the assumption that each recommendation is valid for 2 months. The calculation of portfolio abnormal returns is described in the caption of Table 3. P-values based on two-tailed t-tests are in parentheses.

\begin{tabular}{|c|c|c|c|c|c|c|}
\hline \multirow[t]{2}{*}{ Portfolios } & \multicolumn{6}{|c|}{ Mean monthly abnormal return (\%) (p-value) } \\
\hline & CAPM & & Fama-French & & Four factor & \\
\hline \multicolumn{7}{|c|}{ Panel A: Long portfolios } \\
\hline F1 (most frequent) & 0.517 & $(0.012)$ & 0.372 & $(0.004)$ & 0.488 & $(0.000)$ \\
\hline F2 & 0.421 & $(0.031)$ & 0.329 & $(0.008)$ & 0.444 & $(0.000)$ \\
\hline F3 & 0.420 & $(0.021)$ & 0.284 & $(0.015)$ & 0.372 & $(0.000)$ \\
\hline F4 & 0.302 & $(0.082)$ & 0.214 & $(0.099)$ & 0.371 & $(0.003)$ \\
\hline F5 (least frequent) & 0.222 & $(0.223)$ & 0.124 & $(0.468)$ & 0.241 & $(0.124)$ \\
\hline F1-F5 & 0.295 & $(0.079)$ & 0.248 & $(0.083)$ & 0.247 & $(0.078)$ \\
\hline \multicolumn{7}{|c|}{ Panel B: Short portfolios } \\
\hline F1 (most frequent) & -0.195 & $(0.331)$ & -0.536 & $(0.003)$ & -0.349 & $(0.027)$ \\
\hline $\mathrm{F} 2$ & -0.167 & $(0.412)$ & -0.240 & $(0.118)$ & -0.067 & $(0.521)$ \\
\hline F3 & -0.256 & $(0.199)$ & -0.360 & $(0.021)$ & -0.173 & $(0.129)$ \\
\hline F4 & -0.202 & $(0.273)$ & -0.274 & $(0.062)$ & -0.088 & $(0.471)$ \\
\hline F5 (least frequent) & -0.119 & $(0.535)$ & -0.198 & $(0.263)$ & -0.041 & $(0.788)$ \\
\hline F1-F5 & -0.076 & $(0.350)$ & -0.338 & $(0.049)$ & -0.308 & $(0.064)$ \\
\hline \multicolumn{7}{|c|}{ Panel C: Long-short portfolios } \\
\hline F1 (most frequent) & 0.712 & $(0.000)$ & 0.909 & $(0.000)$ & 0.838 & $(0.000)$ \\
\hline F2 & 0.588 & $(0.000)$ & 0.570 & $(0.000)$ & 0.511 & $(0.000)$ \\
\hline F3 & 0.676 & $(0.000)$ & 0.645 & $(0.000)$ & 0.546 & $(0.000)$ \\
\hline F4 & 0.505 & $(0.000)$ & 0.489 & $(0.000)$ & 0.459 & $(0.000)$ \\
\hline F5 (least frequent) & 0.341 & $(0.002)$ & 0.322 & $(0.001)$ & 0.283 & $(0.002)$ \\
\hline F1-F5 & 0.371 & $(0.019)$ & 0.587 & $(0.001)$ & 0.555 & $(0.002)$ \\
\hline
\end{tabular}


this type of investor behavior, but that their profits relative to the fifth quintile are also much higher. Last, we shorten the holding period for all stocks in our portfolios to a maximum of two months and find that the results remain largely unchanged.

Our results suggest that analysts who revise their recommendations more frequently are more responsive to the market and do not derive their advantage from firms' earnings reports. A significant part of their overall advantage lies in those revisions that follow unusual market activity. Additionally, their higher abnormal returns do not appear to be a result of simply having made more revisions. Our results are consistent with the hypothesis that at least part of the superior profitability of frequently revising analysts could be attributed to their superior skill in uncovering private information. We conclude that investors are better off, both in the short-run and in the long-run, following the advice of analysts who make revisions more frequently.

\section{References}

Asquith, P., Mikhail, M., Au, A., 2005. Information content of equity analyst reports. J. Financ. Econ. 75, $245-282$.

Barber, B., Lehavy, R., McNichols, M., Trueman, B., 2001. Can investors profit from the prophets? Security analyst recommendations and stock returns. J. Finance 56, 531-563.

Barber, B., Lehavy, R., McNichols, M., Trueman, B., 2003. Reassessing the returns to analysts' stock recommendations. Financ. Anal. J. 59, 88-96.

Barber, B., Lehavy, R., Trueman, B., 2007. Comparing the stock recommendation performance of investment banks and independent research firms. J. Financ. Econ. $85,490-517$.

Barber, B., Odean, T., 2000. Trading is hazardous to your wealth: the common stock investment performance of individual investors. J. Finance 55, 773-806.

Barber, B., Odean, T., 2008. All that glitters: the effect of attention and news on the buying behavior of individual and institutional investors. Rev. Financ. Stud. 21 , 785-818.

Bidwell, C., 1977. How good is institutional brokerage research? J. Portf. Manag. 3, 26-31.

Black, F., 1971. Yes, Virginia, there is hope: tests of the value line ranking system. Financ. Anal. J. 29, 10-14.

Bradley, D., Jordan, B., Ritter, J., 2008. Analyst behavior following IPOs: the bubble period evidence. Rev. Financ. Stud. 21, 101-133.

Carhart, M., 1997. On persistence in mutual fund performance. J. Finance 52, 57-82.

Conrad, J., Cornell, B., Landsman, W., Rountree, B., 2005. How do analyst recommendations respond to major news? J. Financ. Quant. Anal. 41 (1), 25-49.

Copeland, T., Mayers, D., 1982. The value line enigma (1965-1978). J. Financ. Econ. 10, 289-321.

Cowles, A., 1933. Can stock market forecasters forecast? Econometrica 1, 309-324.

Da, Z., Engelberg, J., Gao, P., 2011. In search of attention. J. Finance 66, 1461-1499.

Dimson, E., Marsh, P., 1984. An analysis of brokers' and analysts' unpublished forecasts of UK stock returns. J. Finance 39, $1257-1292$.

Dorfman, J., 1991. Analysts devote more time to selling as firms keep scorecard on performance. Wall St. J. C1 (October 29, 1991).

Elton, E., Gruber, M., Grossman, S., 1986. Discrete expectational data and portfolio performance. J. Finance 41, 699-714.

Emery, D., Li, X., 2009. Are the Wall Street analyst rankings popularity contests? J. Financ. Quant. Anal. 44, 411-437.

Ertimur, Y., Sunder, J., Sunder, S., 2007. Measure for measure: the relation between forecast accuracy and recommendation profitability of analysts. J. Account. Res. 45 (June 2007)

Fama, E.F., French, K.R., 1993. Common risk factors in the returns on stocks and bonds. J. Financ. Econ. 33, 3-56.

Fama, E., MacBeth, J., 1973. Risk, return, and equilibrium: empirical tests. J. Polit. Econ. 71, 607-636.

Fang, L., Yasuda, A., 2011. Are Stars' Opinions Worth More? Evidence from Stock Recommendations 1994-2009. SSRN Working Paper.

Galant, D., 1992. Going public. Inst. Investor 127-129.

Grossman, S., Stiglitz, J., 1980. On the impossibility of informationally efficient markets. Am. Econ. Rev. 70, 393-408.

Groth, J., Lewellen, W., Schlarbaum, G., Lease, R., 1979. An analysis of brokerage house securities recommendations. Financ. Anal. J. 35, 32-40.

Jegadeesh, N., Kim, W., 2006. Value of analyst recommendations: international evidence. J. Financ. Mark. 9, 274-309.

Jegadeesh, N., Kim, J., Krische, S., Lee, C., 2004. Analyzing the analysts: when do recommendations add value? J. Finance 59, $1083-1124$.

Kecskes, A., Michaely, R., Womack, K., 2010. What drives the value of analysts' recommendations: earnings estimates or discount rate estimates? Working Paper. Leone, A., Wu, J., 2007. What does it take to become a superstar? Evidence from Institutional Investor rankings of financial analysts. SSRN Working Paper.

Li, X., 2005. The persistence of relative performance in stock recommendations of sell-side financial analysts. J. Account. Econ. 40, $129-132$.

Ljungquist, A., Malloy, C., Marston, F., 2009. Rewriting history. J. Finance 64, 1935-1960.

Logue, D., Tuttle, D., 1973. Brokerage house investment advice. Financ. Rev. 8, 38-54.

Loh, R., Mian, M., 2006. Do accurate earnings forecasts facilitate superior investment recommendations? J. Financ. Econ. 80, $455-483$.

Loh, R., Stulz, R., 2011. When are analyst recommendation changes influential? Rev. Financ. Stud. 24, $593-627$.

Malmendier, U., Shanthikumar, D., 2007. Are small investors naïve about incentives? J. Financ. Econ. 85, 457-489.

Mikhail, M., Walther, B., Willis, R., 2004. Do security analysts exhibit persistence differences in stock picking ability? J. Financ. Econ. 74, 67-91.

Odean, T., 1998. Volume, volatility, price, and profit when all traders are above average. J. Finance 53, 1887-1934.

Ryan, P., Taffler, R., 2004. Are economically significant stock returns and trading volumes driven by firm-specific news releases? J. Bus. Finance Account. 31 (1-2), 49-82.

Schipper, K., 1991. Commentary on analysts' forecasts. Account. Horiz. 5, 105-121.

Stickel, S., 1995. The anatomy of the performance of buy and sell recommendations. Financ. Anal. J. 51, 25-39.

Womack, K., 1996. Do brokerage analysts' recommendations have investment value? J. Finance 51, 137-167.

Yan, X., Zhang, Z., 2009. Institutional investors and equity returns: are short-term institutions better informed? Rev. Financ. Stud. 22, 893-924. 